\title{
DEPRESSÃO NO GÊNERO MASCULINO
}

\section{ARTIGO ORIGINAL}

PICKLER, Cristiane Dandolini ${ }^{1}$

PICKLER, Cristiane Dandolini. Depressão no gênero masculino. Revista Científica Multidisciplinar Núcleo do Conhecimento. Ano 04, Ed. 08, Vol. 04, pp. 86-97. Agosto de 2019. ISSN: 2448-0959, Link de acesso: https://www.nucleodoconhecimento.com.br/psicologia/depressao-no-genero

\section{RESUMO}

O presente ensaio discorre, numa perspectiva psicanalítica, sobre a depressão e suas formas de manifestação no homem. De acordo com pesquisas da Organização Mundial de Saúde (OMS), a depressão está dentre as afecções mentais mais incapacitantes, atingindo atualmente cerca de $15 \%$ da população adulta. A depressão no gênero masculino é um tema pouco abordado em relação a depressão feminina, pois o homem é resistente e apresenta um modo peculiar em lidar com seus problemas e suas afecções. Esta "resistência" parece se refletir até nos meios científicos, considerando que os levantamentos feitos na área apontam lacunas em estudos voltados à depressão no gênero masculino. A partir do caso Giovanni Segantine analisado por Abraham (1909), discípulo de Freud, apresenta os primeiros inscritos sobre a depressão, como ainda os novos referenciais explicativos, de autores contemporâneos, ao que hoje conhecemos como depressão. Todavia, evidencia fundamentar algumas noções e seguir trabalhando na interseção dos "discursos" aqui

1 Doutorando Psicologia Clínica (Psicanálise) pela Universidade de Ciências Empresariais e Sociais - UCES, especialização em Gestão Organizacional pela Universidade do Vale do Itajaí - UNIVALI, graduação em Psicologia pela Universidade do Sul de Santa Catarina - UNISUL. 
apresentados, enfrentando o desafio de articular de forma significativa as interferências que seguem.

Palavras Chave: Psicanálise, depressão, gênero masculino, objeto.

A perda de um objeto amoroso constitui excelente oportunidade para que a ambivalência nas relações amorosas se faça efetiva e manifesta (...) o conflito devido a ambivalência empresta um cunho patológico ao luto, forçando-o a expressar-se sob forma de auto recriminação, no sentido que a própria pessoa enlutada é culpada pela perda do objeto amado, isto é, que ela a desejou. Freud, Luto e Melancolia, 1917.

\section{INTRODUÇÃO}

Segundo pesquisas da Organização Mundial de Saúde (OMS), a depressão está dentre as afecções mentais mais incapacitantes, atingindo atualmente cerca de 15\% da população adulta. Estima-se que em 2020 será a segunda maior causa de incapacitação, com taxa acima de $30 \%$, e, em 2030 , poderá ser a afecção mais prevalente, à frente do câncer e de algumas doenças infecciosas. (OLIVEIRA \& RAMOS, 2015). O fato é que a depressão figura como uma das principais formas de manifestações do sofrimento psíquico no século XXI, um século que teve importantes conquistas tecnológicas, descobertas nas diferentes áreas da ciência e mudanças sociais significativas vinculadas as novas configurações e rearranjos familiares, padrões e papéis e, consequentemente, novas representações atribuídas aos gêneros.

As transformações decorrentes de imposições sociais, culturais e econômicas advindas da contemporaneidade são frenéticas e, na maioria das vezes, rápidas demais para permitirem ao sujeito uma absorção e "adequação" do seu ritmo e significado, o que resulta em uma inegável influência nos processos de subjetivação e formas de enfrentamento dos problemas, principalmente para os homens, que apresentam peculiaridades marcantes no modo de lidar com problemas vinculados a sua saúde. 
A influência dos aspectos sociais e psicológicos parece importante não só na origem propriamente dita dos estados depressivos, mas também no modo de apresentação dos sintomas e na representação que este pode ter para o sujeito e suas relações sócio familiares. A depressão masculina é um assunto pouco abordado em relação a depressão feminina, provavelmente, porque os homens são resistentes em tocar nos seus problemas, tendem a mascarar a depressão por uma série de caminhos e porque, culturalmente, o gênero é sinônimo de pujança.

Ao longo dos tempos, a masculinidade vem sendo constituída, sob "conceitos e preconceitos", na tentativa de encontrar seu próprio sentido, e definir ao imaginário social, o que é ser homem.

De acordo com Almeida, Sales e Lima:

Em nossa sociedade, padrões de gênero são construídos mesmo antes do nascimento do bebê, uma vez que há adequações a modelos de feminilidade e masculinidade já estabelecidos. Algumas implicações acarretadas por determinadas formas de conceber a masculinidade afirmam que a cultura do "macho forte" acarreta uma série de prejuízos para a saúde dos homens em geral. Assim, a saúde do homem tem sido um assunto escanteado, sob o estereotipo social do homem invulnerável. Deste modo, algumas doenças, como a depressão, são associadas apenas ao universo feminino (p.28, 2010).

Esta "resistência" parece se refletir até nos meios científicos, considerando que os levantamentos feitos na área apontam lacunas em estudos voltados à depressão no gênero masculino. Por exemplo, um estudo realizado por Aros (2008) que teve como objetivo avaliar produções científicas sobre depressão com ênfase na depressão masculina e instrumentos utilizados para avaliação, mostrou que menos de $4 \%$ dos artigos escritos estudaram a depressão no gênero masculino.

\section{DEPRESSÃO NA PERSPECTIVA PSICANALÍTICA}

O termo "depressão" não é especificamente próprio da teoria psicanalítica, provém do campo psiquiátrico. No entanto, a psicanálise tem desenvolvido referenciais explicativos ao que hoje conhecemos como depressão. Do ponto de vista 
psicanalítico, a depressão resulta do empobrecimento da vida anímica, decorrente de decepções com seus objetos.

Entre as diversas formas clínicas da depressão, a Melancolia foi, seguramente, aquela que mais chamou a atenção de Freud, e se tornou objeto de um importante estudo metapsicológico, publicado em 1917, com o título: "Luto e Melancolia". Situou os estados de melancolia e depressão no registro da perda, preocupando-se em compreender a maneira como cada sujeito pode reagir psiquicamente à doença. $A$ dificuldade em elaborar perdas e vivenciar um luto está fundamentalmente ligada à melancolia e depressão.

Freud que considerava os objetos como determinantes originários na constituição da subjetividade, a partir do referido estudo, passa a dar mais relevância ao tema. Postulando que na experiência melancólica há a introjeção de uma relação ambivalente entre o ego e o objeto, objeto que nesse caso é inconsciente. A identificação parcial entre o ego e o objeto "perdido" resulta em um processo de grande destrutividade para o ego, na medida em que o ego não consegue se igualar ao objeto introjetado, e assim passa a buscar novos objetos. Freud estabelece ainda, que o objeto pode ter sua existência no psiquismo mesmo depois de não estar mais presente como objeto da percepção.

Outros estudiosos da depressão, como Enbrenberg (1998), acreditam que a nova sociedade e realidade cultural de nosso mundo contemporâneo impõem uma compreensão diferente dos processos depressivo e melancólico. Antes éramos abarcados por uma cultura disciplinar, repressora, e hoje, por cultura com um "modelo de insuficiência”. O melancólico exprimia-se pelas violentas autoacusações, motivadas pelo sentimento de culpa, agora, nesse novo padrão civilizatório, no lugar da culpa, advinda do interdito, aparecem a vergonha e a falta de inciativa, substituindo a "dor moral pela apatia e pelo vazio depressivo".

Delouya (2010) outro autor psicanalista caracteriza a depressão, assim como a dor e a angústia, como um estado afetivo de privação, onde o sujeito é privado das "qualidades e figuras singulares que animam e dotam o afeto de sua especificidade" 
(p. 15). Pontua que devemos compreendê-la como a incapacidade, por mais breve que seja, de exercer ou possuir algo que é essencial para o "viver humano". Ressalta Delouya (2010):

O afeto oriundo do ambiente humano de origem, e sempre dirigido a um outro, ou gerado em relação a ele, abriga em seu bojo uma peculiar disposição para o ser semelhante - uma forma empática de aproximá-lo - que tem no sofrimento um pressuposto e ingrediente fundamental. Portanto, enquanto sofrimentos da alma, a depressão, a dor e a angústia talvez sejam, por essa razão, não somente o cessar ou a privação dos afetos, mas seus protótipos de origens, ou seja, suas formas de base ( $p$. 16).

Bleichamar (1986) pontua a perda do objeto como condição à depressão, ressalta, no entanto, que isto não basta para mostrar em que consiste, é necessário aclarar como se constitui o objeto libidinal, que relação guarda com o desejo, o que deve entenderse por perda de objeto, e especialmente qual é a razão pela qual a perda produz a depressão, "em suas diversas variantes".

Abraham (1909), discípulo de Freud, em seus primeiros estudos sobre a depressão, apresenta o caso de Giovanni Segantini. Nascido próximo de Trento, em 1858, Segantini ficou órfão materno, aos cinco anos, acreditava ser o culpado pela morte de sua mãe. Anteriormente o irmão mais velho havia falecido em um incêndio. $O$ pai o abandonou, logo após a morte da esposa. Abraham propõe uma discussão sobre a melancolia do pintor, que gira em torno da ideia de morte e ressurreição da mãe, culto à sua ausência e presentificação do corpo perdido da mãe. Pontua que essa temática, embora marcante ao longo da obra de Segantini, serve apenas como uma espécie de anteparo para encobrir a um outro ausente: o pai e a ambivalência frente ao seu assassinato. "De acordo com as experiências adquiridas pelo homem, é sempre a mãe que the faz conhecer, nesse período precoce da vida, uma tal decepção." (Abraham apud May, p. 263-4, 2003).

Segantini ao longo de sua vida pintou obras que contemplavam a natureza e diversas figuras femininas, maternas. Passou por momentos difíceis, refugiou-se em seu mundo pictórico, onde encontrou formas de exprimir a sua dor, ou mesmo como Abraham afirmou: seria a reparação de ataques que na fantasia foram feitas ao objeto. 
Abraham de acordo com May (2003) atribuiu a depressão e as crises maníacas ao "complexo materno", exatamente como Freud discorre sobre os desejos edipianos do menino em relação à mãe. Decepcionado, Segantini desejava sua morte. Abraham também considerou que o ódio como descrito por Freud (1905b)

- Foi reprimido no final da infância juntamente com os desejos eróticos, podendo retornar na fase adulta por meio de uma falha na repressão. Esse processo está implícito no quadro Die Bösen Mütter: Como o próprio Segantine afirmou, ele quis, por essas imagens, punir "as mães más... as fúteis e as sensuais despidas" (Abraham apud May, p.174, 2003).

May (2003) coloca que Abraham insistiu numa perspectiva de que a depressão se devia substancialmente à repressão do ódio ou de um sadismo, onde: "se não posso amar as pessoas, tenho que odiá-las". Possivelmente, um funcionamento, na tentativa de evitar novos sofrimentos e decepções. "Na verdade, na visão de Abraham, o paciente estava reprimindo sua hostilidade em relação aos pais e projetando-as em outras pessoas" (p.153, 1927). Hostilidade bem peculiar e característica dos homens com depressão, ainda hoje.

\section{ESTUDOS ATUAIS DEPRESSÃO E GÊNERO}

Alguns estudos indicam que a depressão é mais prevalente entre o sexo feminino, mas há outros que fundamentam as diferenças em decorrência de a depressão estar, na verdade, sub-diagnosticada entre os homens. A doença também afeta os homens, só que eles manifestam de maneira diferente, queixam-se menos: relutam em expor as suas emoções, dificuldades e fragilidades e, por isso, não procuram ajuda. Sofrem como as mulheres, mas escondem-se atrás de comportamentos, na maioria das vezes, agressivos e de risco, os quais, socialmente, são "esperados e aceitos"

Justo e Calil (2006) em estudo baseado em uma revisão narrativa da literatura, que recebe o nome "Depressão - o mesmo acometimento para homens e mulheres", descrevem aspectos epidemiológicos, biológicos, sociais e psicológicos associados às diferenças de gênero nas depressões. Ressaltam que há diversos tipos de diferenças entre os sexos quanto a manifestações depressivas, sendo uma delas a 
proporção à distribuição de duas mulheres para um homem nas taxas de prevalência de depressão maior, amplamente descrita e produto de estudos bem conduzidos. Salienta, no entanto, que permanecem muitas incertezas em aspectos fundamentais acerca do tema.

Liange e George (2012) em um artigo intitulado Men's Experiences of Depression and the Family's Role ingender Socialization: A Phenomenological Study fron Urban South Índia, apresentam um estudo realizado no Department of Psychology, Christ University, Hosur Road, Índia, que investiga as experiências subjetivas dos homens, da depressão e do papel da família na socialização de gênero. O presente estudo utilizou um método de entrevista semi estruturada (Coolican, 2004), com uma amostra de nove homens, que vivem em áreas urbanas do Sul da Índia. Ele mostrou que em geral, os participantes percebiam suas experiências depressivas associadas às experiências familiares precoces, que foram inadequadas e caracterizadas por emotividade restritiva, adversidades, resposta inadequada de enfrentamento, má qualidade da relação pai e filho, a rigidez ao gênero, estereótipos sobre autonomia e expressividade emocional. Propondo assim, uma relação entre a depressão no homem e experiências tempranas inadequadas à socialização do gênero.

$\mathrm{Na}$ Australian Catholic University, de Melbourne, uma pesquisa foi realizada por Rice, Barry e Bambling (2011) sobre Men and depression: the impact of male role norms lifelong. O estudo relata os dados de duas amostras on-line de homens australianos ( $\mathrm{Ns}=343,525)$, com foco em diferenças entre os grupos etários de masculinidade e depressão. De acordo com a previsão, ambas as amostras indicaram relação do aumento da depressão em homens mais velhos. Os resultados são interpretados dentro do contexto de homens com conflitos relacionados ao papel de gênero ao longo da vida.

Na Pontifica Universidade Católica de Campinas, Aros (2008) realizou um estudo intitulado Produções Científicas sobre Depressão: Análise de Resumos (2004-2007) que teve como objetivo avaliar produções científicas sobre depressão com ênfase na depressão masculina e instrumentos utilizados para avaliação. $O$ autor observou dentre os artigos escritos que apenas 3,7\% estudaram a depressão no gênero 
masculino, sendo que nenhum instrumento foi identificado para mensurar exclusivamente a depressão no gênero masculino. Observou, ainda, que todos se referiam apenas a aspectos ligados ao alto estresse: biológico, social e ocupacional, ressaltando a pouca atenção que tem sido dada às diferenças sintomatológicas da depressão no gênero masculino.

Na universidade de Brasília um trabalho foi realizado por Windmöller e Zanello (2016), com o objetivo fazer um levantamento bibliográfico e uma revisão sistemática da literatura brasileira publicada acerca do tema "depressão masculina" entre os anos de 2003 e 2013, nas principais plataformas brasileiras LILACS e SciELO Brasil. Buscouse não apenas mapear esses estudos, mas analisar se e como os estudos das masculinidades têm contribuído para esse campo. Para tanto, foram utilizados oito descritores de gênero e nove de saúde mental/depressão. De forma predominante, o fenômeno da depressão não foi analisado, levando-se em consideração os estudos das masculinidades e de raça/etnia. Além disso, apenas duas pesquisas realizaram entrevistas com os homens, o que aponta a invisibilidade de pesquisas qualitativas e um incipiente número de pesquisas que os escutem. A contribuição do presente estudo é apontar justamente essa lacuna.

\section{CONSIDERAÇÕES}

Observamos, ainda hoje, muitos os mitos e preconceitos em torno da masculinidade, a regularem atitudes e comportamentos. A sociedade está em constante mudança, as mentalidades evoluíram e que o que se espera de homens (e mulheres) é hoje muito diferente de séculos anteriores, apesar de, observamos ainda, muitas incertezas e angústia diante desse "novo" que vem sendo construído. Salientam Burin e Meller (2000), que na atualidade é necessários um debate e uma revisão sobre o tema gênero, visto que está tendo uma suposição 'unificante que nuclearia' a todos os sujeitos.

As referidas autoras ressaltam que devemos compreender esse sujeito em seu contexto histórico, social, político e econômico, bem como as inferências destes, na constituição de sua subjetividade e mal estar. Colocam, entretanto, que deveríamos 
levar em consideração a diversidade atual dos 'distintos modos de posicionamento em seu gênero para os homens'. Alertam-nos para certos cuidados.

Semelhanças de gênero, poderíamos pensar em um processo de desgeneralização ou, talvez, uma cegueira de gênero?

Diante das transformações desencadeadas na transição da modernidade para a contemporaneidade, cabe indagar que efeitos foram provocados na constituição das subjetividades nos tempos de hoje. Na medida em que se percebe a ausência de uma clareza e preparação para esta mudança de exigências no campo do ser, pode-se considerar que as rupturas decorrentes das inegáveis transformações no processo de subjetivação colocam o sujeito, muitas vezes, em um estado de sofrimento frente às dicotomias de demandas que deve atender quase que instantaneamente, sem a possibilidade de elaborações e simbolizações.

A época atual, assevera Studt (2007), se caracteriza por vivências de instáveis e complexas, bem como pelo sentimento de insegurança quanto à capacidade de se viver exitosamente. Segundo a autora, os papéis desempenhados nas diversas relações interpessoais estão cada vez menos definidos, e as gerações passadas já não servem como pontos de referência para atender às necessidades atuais.

A evolução ainda não rompeu todas as barreiras. Existem assuntos que permanecem obscuros, tabus. O mundo das emoções, por exemplo, está longe de ser vivido da mesma maneira por mulheres e homens. E o que elas expressam, falam, eles reprimem, calam. Assim ocorre com a depressão. Podemos entender que o sofrimento acarreta na mesma proporção, no entanto, os homens dificilmente procuram tratamento. Talvez porque receiam colocar-se numa posição de fragilidade, pois assim poderá constituir uma ameaça à sua masculinidade e a todos os papéis que, tradicionalmente, são atribuídos ao homem. Daí a relutância em partilhar o que os perturba com familiares, amigos ou profissionais de saúde.

Provavelmente os sintomas da depressão masculina são idênticos aos da feminina, embora existam pesquisas que busquem identificar eventuais diferenças. Podemos 
observar que a irritabilidade tem sido identificada mais nos homens do que nas mulheres, a par de episódios de ira súbita, de perda de controlo, abuso de substâncias psicoativas, agressividade e comportamentos de risco.

A depressão masculina dificilmente é reconhecida pelos homens, que sofrem pelo o enraizamento de uma cultura patriarcal os levando ao um sofrimento e cristalização. Deparamo-nos mais e mais com atitudes e comportamentos que geram conflitos sociais e familiares. No entanto, aos homens parece haver um esclarecimento enquanto a assunção de que a depressão é uma doença que também faz parte do universo masculino e que deve ser desvelada e elaborada.

Sem dúvida, faz-se necessário seguir trabalhando na interseção dos "discursos" aqui apresentados, enfrentando o desafio de articular de forma significativa as interferências que seguem, voltadas, especialmente para o intrapsíquico, seus vínculos, imaginário social, subjetivação e consequentemente, a depressão no gênero masculino.

\section{REFERÊNCIAS}

ALMEIDA, J. B. L., LIMA, J. V. S., SALES, V. A. (2010) A invisibilidade da depressão em homens: há lugar para dor no masculino? Revista Amazônica, 3 (4), 28-45.

AROS, M. S. (2008). Produções Científicas sobre Depressão: Análise de Resumos (2004-2007). (Tesi de Mestrado). Pontifícia Universidade Católica. Campinas.

BLEICHMAR, B. Hugo. (1986). La depressión: un estudio psicoanalítico. Buenos Aires. Ediciones Nueva Visión.

CALIL, H. M., JUSTOS, L. P. (2006). Depressão - o mesmo acometimento para homens e mulheres. Revista de Psiquiatria Clínica, 33(2), 74-79. Recuperado de http://www.hcnet.usp.br/ipq/revista/vol33/n2/74.html

DELOUYA, Daniel. (2010). Depressão: Clínica Psicanalítica. São Paulo. Casa do Psicólogo. 
FREUD, S. (2006). A história do movimento psicanalítico, Artigos sobre a Metapsicologia e outros trabalhos. Obras completas Sigmund Freud (Vol. 14). Rio de Janeiro: Imago (Trabalho original publicado 1914-1916).

FREUD, S. (2006). Conferências Introdutórias sobre Psicanálise. Obras completas Sigmund Freud (Vol. 16). Rio de Janeiro: Imago (Trabalho original publicado 19151916).

LIANG, Tommy. K. L. e GEORGE, Tony. S. (2012). Men's Experiences of Depression and the Family's Role in Gender Socialization: A Phenomenological Study from Urban South India. Journal of Comparative Family Studies 43(1). Recuperado de http://www.questia.com/library/1G1-279905998/men-s-experiences-of-epressionand-the-family-s-role

MAY, Ulrike. (2003). O conceito de Abraham sobre a "mãe má". Uma contribuição para a história da teoria da depressão. Livro anual de Psicanálise (pp.141-162). (Vol. 17). São Paulo: Escuta.

MELER, I. (2000). La sexualidad masculina. Um estúdio psicoanalítico de género. In: M. Burin, \& I. Meler. Varones: Género e subjetividad masculina (pp. 149-198). Buenos Aires: Paidós.

OLIVETO, P. e RAMOS, R. (29 de julho de 2015). Brasil tem maior incidência de depressão entre países em desenvolvimento [Correio Eletrônico]. Recuperado de http://www.correiobraziliense.com.br

RICE, S., Barry, F. e BAMBLING, M. (2011). Men depression: the impacto of male role normas through out the life spa. Australian Educational and Developmental Psychologist The. 28(2), 133-144. Recuperado de http://search.informit.com.au/documentSumamary;dn876918821282891;res=IELHSS

STUDT, A. C. P. (2007). Novos tempos, novos pais? O ser pai na contemporaneidade. (Dissertação de Mestrado). Pontifícia Universidade Católica do Rio Grande do Sul. Porto Alegre. 
WINDMÖLLER, N. e ZANELLO, Valeska. (2016). Depressão e masculinidade: Uma revisão sistemática da literatura em periódicos brasileiros. Psicologia em Estudo, Maringá. 21, 437-449. Recuperado de http://www.redalyc.org/html/2871/287148579008/

Enviado: Setembro, 2018.

Aprovado: Agosto, 2019. 